\title{
Absolute Isotopic Abundance Ratios and Atomic Weight of Magnesium
}

\author{
Edward J. Catanzaro, Thomas J. Murphy, Ernest L. Garner, and William R. Shields
}

Institute for Materials Research, National Bureau of Standards, Washington, D.C., 20234

(August 16, 1966)

\begin{abstract}
Absolute values have been obtained for the isotopic abundance ratios of magnesium, using surface emission mass spectrometry. Samples of known isotopic composition, prepared from nearly pure separated magnesium isotopes, were used to calibrate the mass spectrometers. The resulting absolute values are ${ }^{25} \mathrm{Mg} /{ }^{24} \mathrm{Mg}=0.12663 \pm 0.00013$ and ${ }^{26} \mathrm{Mg} /{ }^{24} \mathrm{Mg}=0.13932 \pm 0.00026$, yielding an atomic weight $\left({ }^{12} \mathrm{C}=12\right)$ of $24.30497 \pm 0.00044$. The indicated uncertainties are overall limits of error based on 95 percent confidence limits for the mean and allowances for effects of known sources of possible systematic error.
\end{abstract}

Key Words: Absolute ratios, atomic weight, isotopic abundances, magnesium.

\section{Introduction}

The NBS is conducting a long-term program of physical atomic weight determinations using solidsource mass spectrometry. Previous determinations include silver [1], ${ }^{1}$ chlorine [2], copper [3], bromine [4], and chromium [5]. The present work extends the study to magnesium.

$A \cdot$ number of mass spectrometric determinations of magnesium isotope abundances have been reported in the literature, including: Dempster [6], Blewett and Jones [7], White and Cameron [8], Hibbs and Redmond [9], White et al. [10], Daughtry et al. [11], Shima [12], and Catanzaro and Murphy [13]. Of these studies, only the pioneer work of Dempster $\left({ }^{24} \mathrm{Mg}\right.$ $\left.=77.4 \%,{ }^{25} \mathrm{Mg}=11.5 \%,{ }^{26} \mathrm{Mg}=11.1 \%\right)$ and the later works of White and Cameron ${ }^{24} \mathrm{Mg}=78.60 \%,{ }^{25} \mathrm{Mg}$ $\left.=10.11 \%,{ }^{26} \mathrm{Mg}=11.29 \%\right)$ and Hibbs and Redmond $\left({ }^{24} \mathrm{Mg}=78.98 \%,{ }^{25} \mathrm{Mg}=10.03 \%,{ }^{26} \mathrm{Mg}=11.00 \%\right)$ were conducted with the aim, or hope, of measuring absolute values. The results obtained by White and Cameron [8] were accepted as best estimates by the ICAW (1961 Report) while those of Hibbs and Redmond [9], which are virtually identical with the absolute values obtained in the present-study, were apparently ignored. In any case, none of the abovenoted studies included calibration of the instruments with separated magnesium isotope mixtures, so none of the results could be considered absolute.

In the present study the mass spectrometers used were calibrated for bias by the use of samples of

\footnotetext{
${ }^{1}$ Figures in brackets indicate the literature references at the end of this paper.
}

known isotopic composition, prepared from nearly pure separated magnesium isotope samples. The measured biases were then used to obtain the absolute magnesium isotope ratios of a reference sample of magnesium metal. The atomic weight was then calculated using masses from Mattauch et al. (14).

The collector and recorder systems used in this laboratory have been designed so that any biases they may contribute are constant. The only "random" bias associated with the isotopic ratio measurements is due to the mass-dependent fractionation of the isotopes during ionization, and this bias is independent of the isotopic composition of the samples. Thus, for each instrumental system used in this study, a single experimentally determined mass-dependent correction factor is valid over the entire range of isotopic compositions measured [5].

The calibration samples were prepared by mixing aliquots of " $\mathrm{Mg} 24$ " and " $\mathrm{Mg} 26$ " separated isotope solutions. The use of the two extreme-mass isotopes gives the maximum sensitivity for determining the bias in the source region of a mass spectrometer. Four of the six calibration samples were prepared so as to give ${ }^{24} \mathrm{Mg} /{ }^{26} \mathrm{Mg}$ ratios which bracketed the natural ${ }^{24} \mathrm{Mg} /{ }^{25} \mathrm{Mg}$ and ${ }^{24} \mathrm{Mg} /{ }^{26} \mathrm{Mg}$ ratios. Amplifier attenuator positions used for these samples were identical to those used in the reference sample analyses, so that amplifier attenuator corrections were unnecessary. The other two calibration samples had unnatural ${ }^{24} \mathrm{Mg} /{ }^{26} \mathrm{Mg}$ ratios of approximately 1 and 2 and comparison of the correction factors given by these two samples with those given by the four "more-natural" samples served as a test of the single-correction-factor assumption. 


\section{Experimental Procedure}

\subsection{Mass Spectrometry}

Isotopic measurements of the calibration and reference samples were made with two different singlefocusing solid-source mass spectrometers. One instrument, MS -2 , has a 6 -in radius of curvature $60^{\circ}$ analyzer tube and $48^{\circ}$ sector magnet; the other, MS-4, has a 12 -in radius of curvature $68^{\circ}$ analyzer tube and $60^{\circ}$ sector magnet. The electronic components and source and collector design are basically the same in both instruments. A third instrument, MS-3, which is identical with MS-4 except that it has a Z-lens in the source assembly, was used to measure the isotopic compositions of the separated isotope solutions. Triple-filament rhenium-ribbon $(1 \times 30$ mils $)$ sources were used and $\mathrm{Mg}^{+}$currents were measured by means of a vibrating-reed electrometer with an expandedscale recorder. Ratios were measured by varying the magnetic field at constant ion-accelerating potential (8kV on MS-2, $5 \mathrm{kV}$ on MS-4).

The magnesium was deposited on the sample filaments in the form of aqueous solutions containing $5 \mathrm{mg} \mathrm{Mg} / \mathrm{ml}, 5 \mathrm{mg} \mathrm{U} / \mathrm{ml}$, and 10 percent $\mathrm{HNO}_{3}$. The uranyl nitrate was added to all solutions to act as a binding agent, because pure $\mathrm{MgO}$ did not adhere well to rhenium filaments. One drop of solution $(\sim 100$ $\mu \mathrm{gMg})$ was deposited on each sample filament and dried with a heat lamp and an electrical current which was slowly increased until an orange uranium oxide was formed.

To minimize the variability in isotopic fractionation (the ${ }^{24} \mathrm{Mg} /{ }^{26} \mathrm{Mg}$ ratio usually decreased by approximately $0.5 \%$ during an analyses), all analyses were performed in an identical manner. The temperature of the ionizing filament $\left(\sim 2100{ }^{\circ} \mathrm{C}\right)$ was held constant for all analyses by monitoring the strength of the $\mathrm{Re}^{+}$ signal. A strict pattern of filament heating was followed and all data were taken on stable or slowly growing ion signals $\left(5-7 \times 10^{-12} \mathrm{~A}\right.$ on $\mathrm{MS}-2$ and $3-4 \times 10^{-12} \mathrm{~A}$ on MS-4) between 25 and $48 \mathrm{~min}$ after the filaments were turned on. The peak-top data were taken by step-wise changes in the magnet current and each peak-top was monitored for 30 sec. All analyses which did not have the normal signal-growth pattern were discarded. ${ }^{2}$

Ionizing filaments were prebaked $(1 / 2 \mathrm{hr}$ at $5 \mathrm{~A})$ in a vacuum and under a potential field $(300 \mathrm{~V})$ to reduce the $\mathrm{Na}^{+}$signal from the rhenium-ribbon. Although there was no problem in resolving the ${ }^{23} \mathrm{Na}$ and ${ }^{24} \mathrm{Mg}$ peaks, preliminary tests showed that the scattering of secondary electrons produced by large $\mathrm{Na}^{+}$beams could affect the baselines under the ${ }^{25} \mathrm{Mg}$ and ${ }^{26} \mathrm{Mg}$ peaks. The prebaking of the ionizing filaments, combined with the efficient secondary electron suppression grids in the collector, eliminated this problem. Aside from an alcohol wash, the sample filaments were not pretreated in any manner; prebaked sample filaments

2 A detailed description of the analytical procedure is given in reference [15] increased the liklihood of sample flake-off. The magnesium background signal of the entire filament setup was negligible, being $<3 \times 10^{-15} \mathrm{~A}$.

In preliminary studies, a small amount $(<1 \%)$ of source memory was sometimes detected, when samples of significantly different isotopic composition were analyzed back-to-back. Experiments showed that the memory was due to particulate matter which had flaked off the sample filaments, during one or more aborted analyses, and had adhered to the first or second source plates. To insure against this memory effect, the shield and first two plates of the source were replaced with a clean set whenever a sample change was made.

\subsection{Purification of the Separated Isotopes}

Electromagnetically separated ${ }^{24} \mathrm{Mg}$ and ${ }^{26} \mathrm{Mg}$ isotopes, in the form of magnesium oxide, were obtained from the Isotopes Division, Oak Ridge National Laboratory of the Union Carbide Nuclear Company. The ${ }^{24} \mathrm{MgO}$ and ${ }^{26} \mathrm{MgO}$ were designated Series KM, Sample 1256(A) and Series RS, Sample 129(A), respectively. The certificate of analysis accompanying each sample included a semiquantitative spectrographic analysis which indicated that calcium was present in both samples at about the 0.2 percent level and that several other elements could be present at concentrations up to 0.05 percent. To reduce these impurities to a level low enough so that they could not cause a significant error in the determination of the magnesium ion in solutions of these isotopes, the separated isotope samples were further purified by a method, based on work by Bricker and Parker [16] and Brunisholz [17], which had been previously found by this laboratory to be effective in removing these impurities and preparing pure $\mathrm{MgO}$.

Each separated isotope sample was treated as follows: The magnesium oxide (about $1.7 \mathrm{~g}$ ) was dissolved in $15 \mathrm{ml}$ of $(1+1)$ redistilled hydrochloric acid and the solution was filtered and diluted to about 300 $\mathrm{ml}$. To this solution was added a solution containing $13 \mathrm{~g}$ (a $1 \mathrm{~g}$ excess) of (ethylenedinitrilo) tetraacetic acid (EDTA) in sufficient dilute $(1+4) \mathrm{NH}_{4} \mathrm{OH}$ to just dissolve the acid. [The EDTA was purified by dissolving it in sufficient dilute $(1+4) \mathrm{NH}_{4} \mathrm{OH}$ to effect solution and recrystallizing the EDTA by adjusting the $p \mathrm{H}$ of the solution to 1.0 with dilute $(1+4)$ redistilled hydrochloric acid. The recrystallization was repeated twice. The ammonium hydroxide was prepared by passing ammonia gas into water.]

The solution containing the $\mathrm{Mg}$ isotope and EDTA was adjusted to $p \mathrm{H} 4.0$ with dilute $\mathrm{NH}_{4} \mathrm{OH}$ and allowed to stand at room temperature for two days. The magnesium salt of EDTA $\left(\mathrm{MgC}_{10} \mathrm{H}_{14} \mathrm{O}_{8} \mathrm{~N}_{2} \mathrm{H}_{2} \mathrm{O}\right)$ began to form after approximately $1 \mathrm{hr}$ and precipitation was substantially complete $(>98 \%)$ at the end of two days. The precipitated Mg-EDTA salt was recovered by filtering the solution through porous glass and was thoroughly washed with water. The 
salt was dissolved in dilute $\mathrm{NH}_{4} \mathrm{OH}$ and reprecipitated as before. The Mg-EDTA from this second precipitation was transferred to a Vycor dish and dried. The temperature was slowly increased until the salt decomposed, and the residue was converted to $\mathrm{MgO}$ by ignition for $8 \mathrm{hr}$ at $800{ }^{\circ} \mathrm{C}$.

Samples of the purified ${ }^{24} \mathrm{MgO}$ and ${ }^{26} \mathrm{MgO}$ were analyzed by quantitative emission spectrography. The results of these analyses are shown in table 1 . The concentration of each of the detected elements was low enough so that their total could not cause a significant error in the magnesium concentration determinations. To conserve the samples, the alkali metals were not determined. However, tests showed that when natural $\mathrm{MgO}$, to which had been added 0.1 percent each of sodium, potassium, rubidium, and cesium, was purified by this method, none of the alkali metals was detected in the purified product, indicating that the concentration of each had been reduced to less than 0.0001 percent.

TABLE 1. Results of spectrochemical analysis of purified isotope samples

\begin{tabular}{|c|c|c|c|}
\hline \multicolumn{4}{|c|}{ Quantitative (with standards) determinations of concentrations } \\
\hline Element & ${ }^{24} \mathrm{MgO}$ & ${ }^{26} \mathrm{MgO}$ & $\begin{array}{c}\text { Estimated limits } \\
\text { of detection }\end{array}$ \\
\hline $\begin{array}{l}\mathrm{Ag} \\
\mathrm{B} \\
\mathrm{Cd} \\
\mathrm{Cr} \\
\mathrm{Cu} \\
\mathrm{Fe} \\
\mathrm{In} \\
\mathrm{Pb} \\
\mathrm{Mn} \\
\mathrm{Ni} \\
\mathrm{Sn} \\
\mathrm{Si} \\
\mathrm{Ti} \\
\mathrm{V} \\
\mathrm{Zn}\end{array}$ & $\begin{array}{c}p p m \\
10 \\
- \\
- \\
- \\
1 \\
<1 \\
1 \\
- \\
- \\
- \\
- \\
<1 \\
1 \\
- \\
-\end{array}$ & $\begin{array}{c}p p m \\
2 \\
- \\
- \\
- \\
<1 \\
<1 \\
- \\
- \\
- \\
- \\
- \\
<1 \\
- \\
- \\
-\end{array}$ & $\begin{array}{l}p p m \\
0.2 \\
0.2 \\
1 . \\
2 . \\
0.1 \\
0.5 \\
1 . \\
2 . \\
0.5 \\
1 . \\
1 . \\
0.5 \\
1 . \\
5\end{array}$ \\
\hline
\end{tabular}

Semiquantitative (without standards) estimates of concentration ranges

$\begin{array}{lcc} & \% & \% \\ \mathrm{Al} & - & 0.0001-0.001 \\ \mathrm{Ca} & 0.0001-0.001 & <0.0001 \\ \mathrm{Pt} & <0.0001 & <0.0001 \\ \mathrm{Rh} & - & -\end{array}$

Notes: dash (-), not detected; <, less than.

\subsection{Preparation and Magnesium Concentration of the Separated Isotope Solutions}

The purified ${ }^{24} \mathrm{MgO}$ and ${ }^{26} \mathrm{MgO}$ samples were dissolved in dilute $\mathrm{HNO}_{3}$ and the solutions were evaporated to near dryness to eliminate most of the excess nitric acid. The residues were taken up in water and diluted to approximately $40 \mathrm{ml}$. The solutions were then filtered and transferred to $100 \mathrm{ml}$ volumetric flasks whose necks had been cut off so that only about $1 \mathrm{~cm}$ remained. The solutions were then diluted to about $65 \mathrm{ml}$ and thoroughly mixed by swirling the flasks for several minutes. Each flask was then sealed with a rubber serum septum and left overnight in the case of a semimicrobalance, to insure that thermal equilibrium was achieved. The flasks and contents were then weighed on the balance to $\pm 0.02 \mathrm{mg}$. Samples were withdrawn from each flask by inserting a platinum needle, attached with a Kel-F hub to a glass hypodermic syringe, through the rubber septum and withdrawing the desired amount of solution. A second needle which just punctured the septum served as a vent. The syringe and needle were washed with distilled water and the washings were combined with the bulk of the sample in a $100 \mathrm{ml}$ beaker. The weight of the sample was determined from the weights of the flask before and after the withdrawal of solution.

Four samples of from 7 to $8 \mathrm{~g}$ each were withdrawn from each solution by this method. The quantity of magnesium in each of these samples was from 4.0 to 4.5 millimoles ( $\mathrm{mM})$. Each sample was concentrated to a small volume by evaporation and transferred to a $15 \mathrm{ml}$ platinum crucible. The beaker was washed several times with water and the washings were caught in the platinum crucible. As necessary, the contents of the crucible was concentrated by evaporation, to make space for the washings. Two $\mathrm{ml}$ of $(1+1)$ redistilled sulfuric acid was added and the solution was evaporated to constant volume on a steam bath. The crucible and contents were transferred to a hot plate and the temperature was slowly increased until fumes of sulfuric acid were noted. The crucibles were then cooled, the contents taken up in water, and the evaporation to fumes of sulfuric acid was repeated. This process was repeated a third time, to insure removal of nitrate and chloride. [Tests with solutions of natural magnesium nitrate showed that after this sulfuric acid treatment the nitrate content was reduced to less than $0.001 \%$, based on a colormetric determination using brucine sulfate(18). When solutions of natural magnesium chloride were treated in the same manner, the chloride content was reduced to less than $0.0005 \%$, based on a turbidimetric silver analysis(18).]

At this point, the salt contained in the crucible was magnesium bisulfate, $\mathrm{Mg}\left(\mathrm{HSO}_{4}\right)_{2}$, which loses $\mathrm{H}_{2} \mathrm{SO}_{4}$ at about $400{ }^{\circ} \mathrm{C}$, to form $\mathrm{MgSO}_{4}$. After the fumes of sulfuric acid had been driven off the $\mathrm{MgSO}_{4}$ was ignited at $600{ }^{\circ} \mathrm{C}$ overnight in an electric furnace.

The crucible was covered with a small piece of platinum foil and the furnace was cooled to $500{ }^{\circ} \mathrm{C}$. The crucible was transferred to a special individual desiccator which was kept in an oven at $150{ }^{\circ} \mathrm{C}$ to lessen the thermal shock of transfer. [The individual desiccator was constructed by sealing a small glass drying bulb to a $70 \mathrm{ml}$ glass weighing bottle. The drying bulb was packed with $\mathrm{P}_{2} \mathrm{O}_{5}$ and closed with a rubber stopper, when cool.] The desiccator containing the covered crucible was transferred from the oven, cooled, stoppered, and allowed to stand $4 \mathrm{hr}$ to insure that thermal equilibrium was attained. The covered crucible was then weighed against time on a microbalance because of the hygroscopic nature of magnesium sulfate. The weight was recorded each minute for $5 \mathrm{~min}$. The weight at "zero time" was determined from a weight-time plot. The weight of magnesium 
sulfate was equal to the "zero time" weight minus the weight of the crucible and cover. All weights were corrected to vacuum.

This procedure of ignition, cooling, and weighing was repeated until a constant weight was obtained for the magnesium sulfate; that is, until the weighings agreed to within $50 \mu \mathrm{g}$. For simplicity of calculation, the average of the two weighings was converted to millimoles (mM) of magnesium using the 1964 atomic weights [19] for sulfur and oxygen and a calculated atomic weight for the isotopic magnesium based on the ORNL analyses. The results of these determinations are shown in table 2.

This method for the determination of the concentration of the magnesium isotope solutions was adopted after it became apparent that none of the conventional methods for magnesium analysis were capable of yielding precise enough results. It is a valid method as long as the purity of the magnesium sulfate is known. As stated previously, the total of the cationic impurities, as determined by emission spectrography, would cause a negligible error, and the only two likely anionic impurities, nitrate and chloride, would have been reduced to negligible amounts by the repeated sulfuric acid evaporations.

TABLE 2. Concentration of magnesium isotope solutions

\begin{tabular}{|c|c|c|c|c|}
\hline Soln & $\begin{array}{l}\text { Sample } \\
\text { No. }\end{array}$ & Wt soln & $\mathrm{Mg}$ & $\begin{array}{l}\text { Conc. soln } \\
\mathrm{Mg} / \mathrm{g} \text { soln }\end{array}$ \\
\hline \multirow[t]{2}{*}{ "Mg 24" } & $\begin{array}{ll} & 1 \\
1 & \\
2 & \\
3 & \\
4 & \end{array}$ & $\begin{array}{c}g \\
7.53528 \\
7.47788 \\
7.37865 \\
7.20773\end{array}$ & $\begin{array}{c}m M \\
4.203714 \\
4.171849 \\
4.116165 \\
4.020761\end{array}$ & $\begin{array}{c}m M \\
0.557871 \\
.557892 \\
.557848 \\
.557840\end{array}$ \\
\hline & & & \multicolumn{2}{|c|}{ Avg. $0.557863^{\mathrm{a}}$} \\
\hline \multirow[t]{2}{*}{ "Mg 26" } & $\begin{array}{l}1 \\
2 \\
3 \\
4\end{array}$ & $\begin{array}{l}7.43629 \\
7.42701 \\
7.70054 \\
7.59321\end{array}$ & $\begin{array}{l}3.895881 \\
3.890721 \\
4.034620 \\
3.978122\end{array}$ & $\begin{array}{r}0.523901 \\
.523861 \\
.523940 \\
.523905\end{array}$ \\
\hline & & & \multicolumn{2}{|c|}{ Avg. $0.523902^{\mathrm{a}}$} \\
\hline
\end{tabular}

a The standard error of the average is calculated to be 0.000067 and the uncertainty of the value of concentration at the 95 percent confidence level is $0.000141 \mathrm{mM} \mathrm{Mg} / \mathrm{g}$ soln.

This method for determining the concentration of magnesium nitrate solutions was tested on solutions containing known amounts of magnesium. Four such solutions were prepared from high purity $(99.99+\%)$ magnesium metal crystals in the approximate concentration of the isotopic solutions. Four samples containing from 3.8 to $5.5 \mathrm{mM}$ of magnesium were withdrawn from each solution and the magnesium ion concentrations were determined as described above. Comparison of the known and measured concentrations of the four solutions showed that: (a) the concentration of magnesium ion as determined by this method agreed to within 0.01 percent of the known magnesium concentration, (b) systematic errors were negligible, and (c) the analyses of the four solutions were of equal precision.

From these analyses and from the analyses of the separated isotope solutions the standard deviation of an individual measurement of the concentration of a magnesium solution was computed to be $0.000133 \mathrm{mM}$ $\mathrm{Mg} / \mathrm{g}$ soln, with $18 \mathrm{deg}$ of freedom. The standard error of the average of four determinations is therefore

$$
\frac{0.000133}{\sqrt{4}} \text { or } 0.000067 \mathrm{mM} \mathrm{Mg} / \mathrm{g} \text { soln, }
$$

and the uncertainty of the concentration is $2.110 \times 0.000067$ or $0.000141 \mathrm{mM} \mathrm{Mg} / \mathrm{g}$ soln $(95 \%$ confidence limits). This corresponds to an uncertainty of 0.025 percent for solutions containing 0.55 $\mathrm{mM} \mathrm{Mg} / \mathrm{g}$ soln.

\subsection{Isotopic Analyses of the Separated Isotope Solutions}

The separated isotope solutions were analyzed five times each on a 12-in. mass spectrometer equipped with a Z-lens (MS-3). The source was dismantled and thoroughly cleaned before the analyses of each solution; clean sources gave negative memory tests.

Because of the large ratios involved, accurate analysis of the separated isotope solutions required larger ion currents than were used in the analyses of the calibration and reference samples. These larger signals $\left(3-4 \times 10^{-11}\right.$ A) were obtained by a combination of the Z-lens source (a gain of $\times 4$ ) and the use of slightly higher sample filament temperatures. The bias for this analytical set up was zero, as determined by analyses of calibration sample No. I (see below) under the identical analytical conditions.

TABLE 3. Isotopic composition of separated magnesium isotopes used in calibration samples

\begin{tabular}{l|r|r|c}
\hline \hline \multicolumn{3}{c}{ Isotope } & \multicolumn{3}{c}{ Isotopic composition (atom percent) } \\
\hline \multirow{3}{*}{ “Mg 24" } & ${ }^{24} \mathrm{Mg}$ & 99.95642 & \pm 0.00184 a \\
& ${ }^{25} \mathrm{Mg}$ & 0.02707 & \\
& ${ }^{26} \mathrm{Mg}$ & .01651 & \\
& ${ }^{24} \mathrm{Mg}$ & 0.39751 & .44772 \\
${ }^{25} \mathrm{Mg}$ & 99.15477 & \pm 0.00413 \\
& ${ }^{26} \mathrm{Mg}$ & &
\end{tabular}

a The uncertainties are based on the 95 percent confidence limits on the ratio determinations.

The isotopic compositions of the separated isotopes are given in table 3 . The isotopic compositions reported by ORNL are "Mg 24," 99.96 \pm 0.02 atom percent ${ }^{24} \mathrm{Mg}, 0.03 \pm 0.01$ atom percent ${ }^{25} \mathrm{Mg}$, and $<0.02 \pm 0.01$ atom percent ${ }^{26} \mathrm{Mg}$; " $\mathrm{Mg} 26$," $0.42 \pm 0.02$ atom percent ${ }^{24} \mathrm{Mg}, 0.42 \pm 0.02$ atom percent ${ }^{25} \mathrm{Mg}$, and $99.16 \pm 0.05$ atom percent ${ }^{26} \mathrm{Mg}$. The ORNL limits quoted express the precision of the measurements. From known sources of systematic error, the absolute error is estimated by ORNL to be less than 1 percent.

\subsection{Preparation of the Calibration Samples}

Six calibration samples were prepared by mixing weighed portions of the "Mg 24" and "Mg 26" solutions to produce ratios ranging from ${ }^{24} \mathrm{Mg} /{ }^{26} \mathrm{Mg}=1$ to 
${ }^{24} \mathrm{Mg} /{ }^{26} \mathrm{Mg}=8.2$ (table 4). The portions were withdrawn from the flasks and weighed in the manner previously described. To eliminate any possibility of change in concentration of the isotope solutions with time, the portions for the calibration samples were withdrawn from the flasks on the same day that the samples for determining the magnesium concentration were withdrawn.

TABLE 4. Composition of magnesium calibration samples

\begin{tabular}{c|c|c|c|c}
\hline \hline $\begin{array}{c}\text { Sample } \\
\text { No. }\end{array}$ & $\begin{array}{c}\text { Isotope } \\
\text { Mg }\end{array}$ & Wt soln & $\begin{array}{c}\text { Conc. soln } \\
\text { Mg/g soln }\end{array}$ & Magnesium \\
\hline \multirow{3}{*}{ I } & & $\begin{array}{c}g \\
m M\end{array}$ & $m M$ \\
& 24 & 1.01244 & 0.557863 & 0.564803 \\
II & 26 & 1.08547 & .523902 & .568680 \\
& 24 & 2.01208 & .557863 & 1.122465 \\
III & 26 & 1.14635 & .523902 & 0.600575 \\
& 24 & 5.17735 & .557863 & 2.888252 \\
IV & 26 & 0.83234 & .523902 & 0.436065 \\
& 24 & 4.92722 & .557863 & 2.748714 \\
V & 26 & 0.64225 & .523902 & 0.336476 \\
& 24 & 5.01471 & .557863 & 2.797521 \\
VI & 26 & 0.77441 & .523902 & 0.405715 \\
& 24 & 5.13324 & .557863 & 2.863645 \\
& 26 & 0.74109 & .523902 & 0.388259 \\
\hline
\end{tabular}

Each calibration sample was thoroughly mixed by stirring, and concentrated to a small volume by evaporation on a steam bath. Since pure $\mathrm{MgO}$ did not adhere well to the rhenium filaments, uranyl nitrate was added to act as a binding agent. The uranyl nitrate was prepared from standard reference material $950 \mathrm{a}, \mathrm{U}_{3} \mathrm{O}_{8}$, uranium chemical standard, which has a magnesium content of only one part per million. Sufficient nitric acid was added so that the final solution contained $5 \mathrm{mg} \mathrm{Mg} / \mathrm{ml}+5 \mathrm{mg} \mathrm{U} / \mathrm{ml}$ and was 10 percent $\mathrm{HNO}_{3}$.

\subsection{Isotopic Analyses of the Calibration and Reference Samples}

Three complete sets of analyses of the calibration and reference samples were made, two on MS-2 and one on MS-4. Each set consisted of eight analyses of the reference, in four sets of two, and two analyses (made in succession) each of the six calibration samples; with duplicate reference analyses being made before and after successive duplicate analyses of two calibration samples. The ${ }^{24} \mathrm{Mg} /{ }^{25} \mathrm{Mg}$ and ${ }^{24} \mathrm{Mg} /{ }^{26} \mathrm{Mg}$ ratios were measured in the analyses of the reference sample but only the ${ }^{24} \mathrm{Mg} /{ }^{26} \mathrm{Mg}$ ratio was measured in the analyses of the calibration samples.

The entire source was dismantled and cleaned between the two complete sets of analyses on MS-2. The shields and first two plates of all sources were replaced with clean st ts whenever a sample change was made. With this precaution, no memory effects were noted.

\section{Results and Discussion}

Table 5 summarizes the results for the six calibration samples. The mean correction factors given in this table and used in subsequent calculations are averages of the results of only the four calibration samples with approximately normal ${ }^{24} \mathrm{Mg} /{ }^{26} \mathrm{Mg}$ ratios (III, IV, V, and VI). The two "abnormal" calibration samples (I and II) were prepared and analyzed to show that the bias (per mass unit) of each instrument is single valued over the entire range of isotopic composition. The agreement between results is well within analytical error. Had the results for calibration samples I and II been included in the averaging for the final correction factors, an estimate of possible amplifier attenuator errors would have had to have been included in the final error statements, since the attenuator positions used in the analyses of these two samples were different from those used in the analyses of the reference sample.

The differences between the correction factors for MS-2, MS-4, and MS-3 (zero bias) is due primarily to the different techniques used on each instrument. The ${ }^{24} \mathrm{Mg} /{ }^{26} \mathrm{Mg}$ and ${ }^{24} \mathrm{Mg} /{ }^{25} \mathrm{Mg}$ ratios decrease steadily during an analysis; the higher the sample filament temperature, the higher the rate of change of these ratios. The technique used in MS-4 included the lowest sample filament temperature and smallest ion signals. This technique gave the smallest change in ratio with time, resulting in the best precision, but highest observed bias.

TABLE 5. Determination of mass spectrometric bias

\begin{tabular}{|c|c|c|c|c|c|c|}
\hline \multirow{2}{*}{$\begin{array}{c}\text { Calibra- } \\
\text { tion } \\
\text { sample } \\
\text { No. }\end{array}$} & \multicolumn{4}{|c|}{ Isotopic ratio, ${ }^{24} \mathrm{Mg} /{ }^{26} \mathrm{Mg}$} & \multicolumn{2}{|c|}{$\begin{array}{l}\text { Correction factor } \\
(2 \text { mass units })\end{array}$} \\
\hline & Calc. & $\mathrm{MS}-2(\mathrm{a})$ & $\mathrm{MS}-2(\mathrm{~b})$ & $\mathrm{MS}-4$ & $\begin{array}{c}\text { MS -2 } \\
(\text { Avg. } a+b)\end{array}$ & $\mathrm{MS}-4$ \\
\hline $\begin{array}{l}\text { I } \\
\text { II } \\
\text { III } \\
\text { IV } \\
\text { V } \\
\text { VI }\end{array}$ & $\begin{array}{l}1.005055 \\
1.88752 \\
6.67364 \\
8.22798 \\
6.94706 \\
7.43012\end{array}$ & $\begin{array}{l}1.01045 \\
1.89905 \\
6.72875 \\
8.27785 \\
7.01270 \\
7.50615\end{array}$ & $\begin{array}{l}1.01270 \\
1.90170 \\
6.71645 \\
8.30795 \\
7.01215 \\
7.47955\end{array}$ & $\begin{array}{l}1.02055 \\
1.91525 \\
6.77655 \\
8.33550 \\
7.04800 \\
7.53350\end{array}$ & $\begin{array}{r}0.993556 \\
.993231 \\
.992718 \\
.992174 \\
.990679 \\
.991631\end{array}$ & $\begin{array}{r}0.984817 \\
.985521 \\
.984814 \\
.987101 \\
.985678 \\
.986277\end{array}$ \\
\hline \multicolumn{5}{|c|}{ 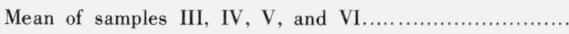 } & 0.991801 & 0.985968 \\
\hline
\end{tabular}

Table 6 gives the observed and corrected magnesium isotope ratios for each mass spectrometer, and the average values, with uncertainty components. The correction factors for ${ }^{25} \mathrm{Mg} /{ }^{24} \mathrm{Mg}$ were calculated by assuming the biases to be one-half of those measured for the ${ }^{26} \mathrm{Mg} /{ }^{24} \mathrm{Mg}$ ratios. The statistical error per analysis was somewhat greater for MS-2 than for MS-4. However, since two sets of analyses were obtained on MS-2, the final standard errors for each mass spectrometer were almost identical and they were given equal weight in the averaging.

With the nuclidic masses given by Mattauch et al. (14), the results yield an atomic weight of 24.30497 \pm 0.00044 on the unified scale $\left({ }^{12} \mathrm{C}=12\right)$. These cal- 
TABLE 6. Observed and corrected isotope ratios for the reference sample

\begin{tabular}{|c|c|c|c|c|c|c|}
\hline \multirow{2}{*}{$\begin{array}{l}\text { Mass } \\
\text { spec- } \\
\text { trom- } \\
\text { eter }\end{array}$} & \multicolumn{2}{|c|}{ Observed ratios } & \multicolumn{2}{|c|}{ Correction factors } & \multicolumn{2}{|c|}{ Corrected ratios } \\
\hline & ${ }^{25} \mathrm{Mg} /{ }^{24} \mathrm{Mg}$ & ${ }^{26} \mathrm{Mg} /{ }^{24} \mathrm{Mg}$ & ${ }^{25} \mathrm{Mg} /{ }^{24} \mathrm{Mg}$ & ${ }^{26} \mathrm{Mg} /{ }^{24} \mathrm{Mg}$ & ${ }^{25} \mathrm{Mg} /{ }^{24} \mathrm{Mg}$ & ${ }^{26} \mathrm{Mg} /{ }^{24} \mathrm{Mg}$ \\
\hline \multicolumn{5}{|c|}{$\begin{array}{l}95 \text { percent confidence limits on ratio determination } \\
\text { Bounds due to possible systematic error in chemical } \\
\text { analyses } \\
\text { Bounds due to possible systematic error in isotopic } \\
\text { composition of separated isotopes }\end{array}$} & $\begin{array}{r}0.1266618 \\
.1265941 \\
0.1266280 \\
\pm 0.0001255 \\
\pm 0.0000812 \\
\pm 0.0000398 \\
\pm 0.0000045\end{array}$ & $\begin{array}{r}0.1393799 \\
.1392556 \\
0.1393178 \\
\pm 0.0002621 \\
\pm 0.0001652 \\
\pm 0.0000870 \\
\pm 0.0000099\end{array}$ \\
\hline
\end{tabular}

a The standard errors for the final results of both mass spectrometers were approximately the same so the results are averaged with equal weight.

b The overall limit of error is the sum of the 95 percent confidence limits for the ratio determinations and the terms covering effects of known sources of possible systematic error.

TABLE 7. Summary calculations of the atomic weight of magnesium

\begin{tabular}{|c|c|c|c|c|c|}
\hline & \multirow[b]{2}{*}{ Value } & \multirow[b]{2}{*}{$\begin{array}{l}\text { Overall } \\
\text { limit of } \\
\text { error }^{\text {a }}\end{array}$} & \multicolumn{3}{|c|}{ Uncertainty components } \\
\hline & & & $\begin{array}{c}\text { Mass } \\
\text { spectrometric } \\
\text { analytical } \\
\text { error }\end{array}$ & $\begin{array}{l}\text { Possible } \\
\text { systematic } \\
\text { error in } \\
\text { chemical } \\
\text { analyses }\end{array}$ & $\begin{array}{l}\text { Possible } \\
\text { systematic } \\
\text { error in } \\
\text { composition } \\
\text { of separated } \\
\text { isotopes }\end{array}$ \\
\hline $\begin{array}{l}\text { Atomic } \\
\text { weight }\end{array}$ & 24.30497 & \pm 0.00044 & $\pm 0.00026^{d}$ & \pm 0.00016 & \pm 0.00002 \\
\hline $\begin{array}{l}\text { Nuclidic } \mathrm{n} \\
\qquad \begin{array}{l}\left({ }^{12} \mathrm{C}=1\right. \\
{ }^{24} \mathrm{Mg} \\
{ }^{25} \mathrm{Mg} \\
{ }^{26} \mathrm{Mg}\end{array}\end{array}$ & 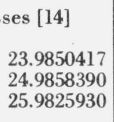 & $\begin{array}{l} \pm .0000019 \\
\pm .0000020 \\
\pm .0000020\end{array}$ & & & \\
\hline $\begin{array}{l}\text { Atorn per } \\
{ }^{24} \mathrm{Mg} \\
{ }^{25} \mathrm{Mg} \\
{ }^{26} \mathrm{Mg}\end{array}$ & $\begin{array}{l}78.992 \\
10.003 \\
11.005\end{array}$ & $\begin{array}{l} \pm .025 \\
\pm .009 \\
\pm .019\end{array}$ & $\begin{array}{l} \pm .0154^{d} \\
\pm .0071^{d} \\
\pm .0123^{d}\end{array}$ & $\begin{array}{l} \pm .0082 \\
\pm .0021 \\
\pm .0058\end{array}$ & $\begin{array}{l} \pm .0009 \\
\pm .0002 \\
\pm .0007\end{array}$ \\
\hline $\begin{array}{c}\text { Isotopic } r \\
25 / 24 \\
26 / 24\end{array}$ & $\begin{array}{l}0.12663 \\
.13932\end{array}$ & $\begin{array}{l} \pm .00013 \\
\pm .00026\end{array}$ & $\begin{array}{l} \pm .000081^{c} \\
\pm .000165^{c}\end{array}$ & $\begin{array}{l} \pm .000040 \\
\pm .000087\end{array}$ & $\begin{array}{l} \pm .000005 \\
\pm .000010\end{array}$ \\
\hline
\end{tabular}

a The overall limit of error is the sum of the limits based on the 95 percent confidence limits for the ratio determinations and the terms covering effects of known sources of possible systematic error.

${ }^{\mathrm{b}}$ From table 6.

c 95 percent confidence limits.

${ }^{d}$ Limits based on 95 percent confidence limits on isotopic ratios. culations are summarized in table 7 . The value given here is significantly different from that presently accepted by the ICAW(24.312).

Catanzaro and Murphy [13] report no variations in the isotopic composition of 60 samples of natural magnesium from various localities and origins, so the atomic weight of magnesium should be constant.

We are indebted to Mrs. Martha Darr for the spectrochemical analysis of the magnesium isotope samples and to Hsien $\mathrm{H}$. Ku for the statistical analysis of the experimental data.

\section{References}

[1] W. R. Shields, E. L. Garner, and V. H. Dibeler, J. Res. NBS 66A (Phys. and Chem.), No. 1, 1 (1962).

[2] W. R. Shields, T. J. Murphy, E. L. Garner, and V. H. Dibeler, J. Am. Chem. Soc. 84, 1519 (1962).

[3] W. R. Shields, T. J. Murphy, and E. L. Garner, J. Res. NBS $68 \mathrm{~A}$ (Phys. and Chem.), No. 6, 589 (1964).

[4] E. J. Catanzaro, T. J. Murphy, E. L. Garner, and W. R. Shields, J. Res. NBS 68A (Phys. and Chem.), No. 6, 593 (1964).

[5] W. R. Shields, T. J. Murphy, E. J. Catanzaro, and E. L. Garner, J. Res. NBS 70A (Phys. and Chem.), No. 2, 193 (1966).

[6] A. J. Dempster, Phys. Rev. 18, 421 (1921).

[7] J. P. Blewett and E. J. Jones, Phys. Rev. 50, 464 (1936).

[8] J. R. White and A. E. Cameron, Phys. Rev. 74, 991 (1948).

[9] R. F. Hibbs and J. W. Redmond, Y-290, AECU-24 Dep. (1948).

[10] J. R. White, T. L. Collins, and F. M. Rourke, Phys. Rev. 101, 1786 (1956).

[11] A. C. Daughtry, D. Perry, and M. Williams, Geochim. Cosmochim. Acta 26, 857 (1962).

[12] M. Shima, Bull. Chem. Soc. Japan 3 7, 284 (1964).

[13] E. J. Catanzaro and T. J. Murphy, J. Geophys. Res. 71, 1271 (1966).

[14] J. H. E. Mattauch, W. Thiele, and A. H. Wapstra, Nuclear Physics 67, 1 (1965).

[15] W. R. Shields, editor, NBS Tech. Note 277, 1966.

[16] C. E. Bricker and G. H. Parker, Anal. Chem. 29, 1470 (1957).

[17] G. Brunisholz, Chima. (Switz.) 11, 363 (1959).

[18] Committee on Analytical Reagents, Reagent ChemicalsAmerican Chemical Society Specifications 1960, p. 289 (Amer. Chem. Society, Wash., D.C., 1961).

[19] A. E. Cameron and E. Wichers, J. Am. Chem. Soc. 84, 4175 (1962).

(Paper 70A6-416) 